\title{
Granulomatous cheilitis
}

\author{
${ }^{1} \mathrm{MF}$ Baqai, ${ }^{2} \mathrm{MT}$ Baqai, ${ }^{3} \mathrm{~T}$ Kashif \\ ${ }^{1}$ Acute Medicine Speciality Trainee, Leeds Teaching Hospital, UK, ${ }^{2}$ Professor of Medicine, AJK Medical College, Azad Kashmir, Pakistan; \\ ${ }^{3}$ Postgraduate Trainee, Cardiology, Shifa International Hospital, Islamabad, Pakistan
}

ABSTRACT A 19-year-old labourer presented with progressively worsening swelling of both lips. Clinical assessment and investigations led to the diagnosis of granulomatous cheilitis.

KEYWORDS Granulomatous cheilitis, orofacial granulomatosis, sarcoidosis

DECLARATION OF INTERESTS No conflicts of interest declared.
Correspondence to MT Baqai,

House No 3,

Street 46, F-8/I

Islamabad

Pakistan

tel. +923005543228

e-mail

mtariqbaqai@hotmail.com

\section{CASE REPORT}

A 19-year-old man presented to the outpatient department of our hospital with progressive swelling of both lips over the preceding six years and worsening over the previous 12 months. There was no history of trauma, skin lesion, facial muscle weakness, febrile episodes, bowel disturbances or swelling in the neck. There was no significant past medical or surgical history. He was not on any medications and denied use of drugs, food or contact allergies. On examination, he had a strong physical appearance, with diffusely enlarged upper and lower lips. His lower lip was more swollen than the upper lip and his tongue was normal. Oral hygiene was good, with no evidence of dental infection. There were no palpable lymph nodes. Cranial nerves examination was normal. He was haemodynamically stable and a systemic examination was unremarkable.

\section{INVESTIGATIONS}

Initial investigations showed a normal blood count, biochemical profile and $\mathrm{Cl}$ esterase level. Angiotensinconverting-enzyme (ACE) levels were raised, at 120 units $/ \mathrm{mL}$. The Mantoux tuberculin skin test was negative. An upper gastrointestinal endoscopy showed no abnormality. A chest X-ray and computed tomography (CT) scan of the chest did not show lymphadenopathy or any evidence of tuberculosis. A lower lip biopsy showed non-caseating granulomas.

\section{MANAGEMENT}

The patient was referred to the dermatology department. He received weekly triamcinolone (10 mg) intralesional injections over the course of six weeks. He was advised to continue these injections for at least three months. However, due to his perceived lack of improvement, and pain induced by the injections, the patient declined any further intralesional injections.

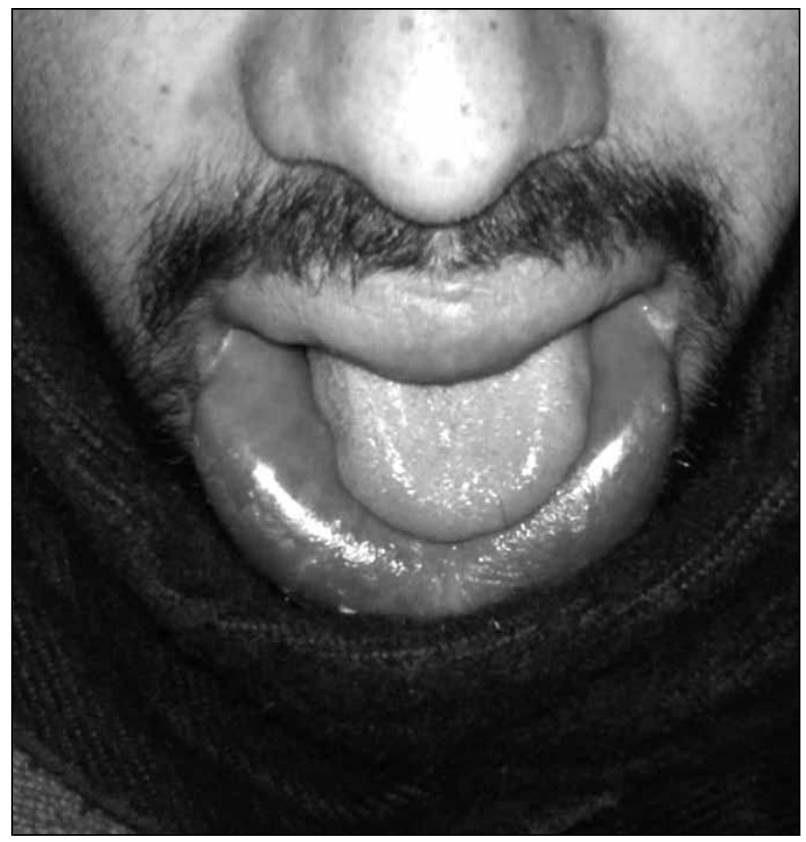

FIGURE I Swelling of upper and lower lip.

Subsequently he was given a course of oral steroids for the next two months $(\mathrm{l} \mathrm{mg} / \mathrm{kg})$. He did not show any improvement. The patient declined any further injections after receiving six steroid injections. Azathioprine ( $\mathrm{l} \mathrm{mg} / \mathrm{kg} /$ day) and sulfa salazine $(500 \mathrm{mgm}$, every six hours) were added to the regimen. He persevered with oral medication for ten weeks with no significant improvement. The patient then requested a referral to the plastic surgery department. The patient was evaluated for surgery. The procedure was explained and he was asked to arrange the required payment. He did not attend for a follow-up appointment. 


\section{DISCUSSION}

Orofacial granulomatosis (OFG) is a rare condition of unknown aetiology used to describe swelling in the lips, face or areas within the mouth, in the absence of any recognised systemic conditions. The term was first introduced by Wiesenfeld in 1985.

Granulomatous cheilitis (GC), first described by Miescher in 1945, ${ }^{2}$ refers to persistent, painless swelling confined to one or both lips. It is regarded as a monosymptomatic manifestation of MelkerssonRosenthal syndrome, ${ }^{3}$ a triad of facial palsy, fissured tongue and GC.

The cause of OFG is unclear. ${ }^{4} \mathrm{~A}$ variety of foodstuffs, including wheat and dairy products, chocolate, eggs, peanuts, cocoa, cinnamaldehyde, monosodium glutamate, cormosine, food additives, toothpaste, and dental material such as amalgam and mercury have been suggested in several case reports. ${ }^{4}$ Some studies consider OFG to be the oral manifestation of Crohn's disease. ${ }^{5,6}$ Differential diagnoses include acquired and hereditary angioedema leprosy, tuberculosis ${ }^{7}$ and sarcoidosis. ${ }^{8}$ The median age of presentation is $25-28$ years old. ${ }^{9}$

The first episode of oedema subsides completely in hours or days. After recurrent attacks, which may range from days to years, swelling may persist and progressively increase, eventually becoming permanent. ${ }^{9}$ Attacks are sometimes accompanied with fever and mild constitutional symptoms such as headache and visual disturbances. The main presenting complaint in a series of II9 patients was facial lip swelling.

\section{REFERENCES}

I Wiesenfeld D, Ferguson MM, Mitchell DN et al. Orofacial granulomatous a clinical and pathological analysis. QJ Med 1985; 54:10I-3.

2 Miescher G. Uber essentielle granulomatose. Makrocheilie (Cheilitis granulomatosa). Dermatologica 1945; 91:57-85. http:// dx.doi.org/I0.I I59/000255774

3 Melkersson E. Case of recurrent facial paralysis with angioneurotic edema. Hugeia 1928; 90:737-4I.

4 Tilakaratne WM, Freysdottir J, Fortune F. Orofacial granulomatosis: review on aetiology and pathogenesis. J Oral Pathol Med 2008; 37: I9I-5. http://dx.doi.org/I0.I I I I/j.I600-07|4.2007.0059I.x

5 van de Scheur MR, van der Waal RI, Volker-Dieben HJ et al. Orofacial granulomatosis in a patient with Crohn's disease. J Am Acad Dermatol 2003; 49:952-4. http://dx.doi.org/10.1016/S01909622(03)01560-3

6 Plauth M, Jenss H, Meyle J. Oral manifestation of Crohn's disease. An analysis of 79 cases. J Clin Gastroenterol 1991; 13:29-37. http:// dx.doi.org/I0.1097/00004836-199/02000-00008

7 Apaydin R, Bahadir S, Kaklikkaya $\mathrm{N}$ et al. Possible role of Mycobacterium tuberculosis complex in Melkersson-Rosenthol syndrome demonstrated with Gene-Probe amplified Mycobacterium tuberculosis direct test. Australas J Dermatol 2004; 45:94-9. http:// dx.doi.org/I0.I I I I/j. I440-0960.2004.0007I.x
Depending on the patient's symptoms and a systemic review, evaluation includes a complete blood count, ACE levels, $\mathrm{Cl}$ esterase level, tuberculosis skin tests and patch tests. Patch tests have identified sensitivities to various foodstuffs and additives, most commonly to benzoic acid. ${ }^{10,11}$ Gastrointestinal endoscopy, gallium scan or positron emission tomography (PET) scanning may be performed. A panoramic scanning dental X-ray may be obtained to exclude chronic dental abscess.

Spontaneous remission is rare. Treatment has been challenging. ${ }^{2}$ No standard or predictably successful modality has been established. Corticosteroids (local or oral) have been advocated ${ }^{13}$ and improvement has been reported, however it is temporary. Antibiotics, sulpha drugs, tetracycline, isoniazid, minocycline, roxithromycin, ${ }^{14}$ and metronidazole have all been tried. Immune modulators such as infliximab ${ }^{15}$ and methotrexate have also been reported. Elimination diets have been recommended. Cinnamon- and benzoate-free diets have shown to be of benefit in a significant number of patients. ${ }^{16,17}$ However a European series showed only a small benefit from cinnamon- and benzoate-free diets in those that patch tested positive for benzoic acid, cinnamaldehyde and cinnamyml alcohol. ${ }^{18}$ Surgical treatment is an option for those patients who are severely affected or have impairment of function. ${ }^{19}$

\section{CONCLUSION}

Chronic swelling of lips is a difficult problem to diagnose and manage. It is a socially embarrassing condition. Management depends on the underlying cause. There is no consensus on the best treatment option. A benzoate cinnamon-free diet has shown benefit in some studies.

8 Bourgeois-Droin C, Harvard S, Granier F et al. Granulomatous cheilitis in two children with Sarcoidosis.J Am Acad Dermatol 1993; 29:822-4. http://dx.doi.org/10.1016/0190-9622(93)70246-P

9 McCartan BE, Healy CM, McCreary CE et al. Characteristics of patients with orofacial granulomatosis. Oral Dis 2011: 17:696-704.

10 Endo H, Rees TD. Cinnamon products as a possible etiologic factor in orofacial granulomatosis. Med Oral Patol Cir Bucal 2007; 12:440-4.

I I Fitzpatrick L, Healy CM, McCartan BE et al. Patch testing for foodassociated allergies in orofacial granulomatosis. J Oral Pathol Med 201 I;40:10-13. http://dx.doi.org/I0.1 I I I/j.1600-07/4.2010.00957.x

12 Banks T, Gada S. A comprehensive review of current treatments for granulomatous cheilitis. Br J Dermatol 20I2; 166:934-7.

13 Perez-Calderon R, Gonzalo-Garijo MA, Chaves A et al. Cheilitis granulomatosa of Melkersson-Rosenthal syndrome: treatment with intralesional corticosteroid injections. Allergol Immunopathol 2004; 32:36-8.

I4 Ishiguro E, Hatamochi A, HamasakiY et al. Successful treatment of granulomatous cheilitis with roxithromycin. J Dermatol 2008; 35:598-600. http://dx.doi.org/I0. I I I I/j. I365-2036.20I I.04792.x

I5 Barry O, Barry J, Langans et al. Treatment of granulomatous cheilitis with infliximab. Arch Dermatol 2005; 141:1080-2. http:// dx.doi.org/10.1001/archderm. I4I.9.1080 
I6 Campbell HE, Escudier MP, Patel P et al. Review article: cinnamonand benzoate-free diet as a primary treatment for orofacial granulomatosis. Aliment Pharmacol Ther 20I I; 34:687-70I. http:// dx.doi.org/I0.I I I I/j.I365-2036.20I I.04792.x

17 White $A$, Nunes $C$, Escudier $M$ et al. Improvement in orofacial granulomatosis on a cinnamon- and benzoate-free diet. Inflamm Bowel Dis 2006; 12:508-I4. http://dx.doi.org/I0.I00I/archderm I4I.6.779-C
18 Morales C, Penarrocha M, Bagan JV et al. Immunological study of Melkersson-Rosenthal syndrome. Lack of response to food additive challenge. Clin Exp Allergy 1995; 25:260-4. http://dx.doi. org/I0.IIII/j.I365-2222.1995.tb01038.x

19 Kruse-Losler B, Presser D, Metze D et al. Surgical treatment of persistent macrocheilia in patients with Melkersson-Rosenthal syndrome and cheilitis granulomatosa. Arch Dermatol 2005; |4|:|085-9|. http://dx.doi.org//0.1001/archderm. I4I.9.1085

\section{Myre Sim Fund Research \& Travel Grants}

Dr Myre Sim (1915-2009) was a renowned and published psychiatrist who assisted many individuals and organisations through his long and successful career, in addition to making a major contribution to the medical community. He was brought up and educated in Edinburgh and graduated MBChB from Edinburgh University in 1938. Although he did not remain in Edinburgh to practice medicine, he retained a great fondness for the Edinburgh University Medical School and the Royal College of Physicians of Edinburgh. He became a Fellow of the Royal College of Physicians of Edinburgh in 1970.

During his lifetime Dr Myre Sim made a series of generous donations to the College. These are now administered by the Myre Sim Committee which meets twice a year, in May and November.

- Eligibility: Available to Fellows and Collegiate members of the RCPE and for any medical graduates of the University of Edinburgh.

- Nature of award: Any activity which assists a viable research project will be considered, including payments for secretarial, library or computer facilities or nursing, laboratory or student assistance. A grant may also be given to assist with travel expenses to attend scientific meetings, courses of postgraduate education, visits to special clinics and other educational activities.

- Specialty: All

- Amount of Award: Up to a maximum of $£ 2,000$ and not intended to be salary supporting. Preference is given to those who have not had advantage of an academic or research post in the last five years. A short paper reporting on the research or activity undertaken will be required.

- Closing date for applications: Applications will be considered bi-annually. Closing dates for applications are 31 March and 30 September each year

- How to apply: Applications forms can be found on the RCPE website or alternatively please contact:

Mrs Roselin Combe

Secretary to the Myre Sim Committee

Direct Tel: 01312473601

E-mail: r.combe@rcpe.ac.uk 